Article

\title{
Drying and Wetting Trends and Vegetation Covariations in the Drylands of China
}

\author{
Chuanzhuang Liang ${ }^{1}$, Tiexi Chen ${ }^{1, *}$, Han Dolman ${ }^{1,2}{ }^{\oplus}$, Tingting Shi ${ }^{3, *}$, Xueqiong Wei ${ }^{1}$, \\ Jialu $\mathrm{Xu}^{4}$ and Daniel Fiifi Tawia Hagan ${ }^{1}$ \\ 1 School of Geographical Sciences, Nanjing University of Information Science and Technology, \\ Nanjing 210044, China; mrczliang@163.com (C.L.); han.dolman@vu.nl (H.D.); \\ xueqiong.wei@nuist.edu.cn (X.W.); dhagan@yeah.net (D.F.T.H.) \\ 2 Department of Earth Sciences, Free University Amsterdam, 1081 HV Amsterdam, The Netherlands \\ 3 School of Applied Meteorology, Nanjing University of Information Science and Technology, \\ Nanjing 210044, China \\ 4 Office of the University President, Nanjing University of Information Science and Technology, \\ Nanjing 210044, China; xujialu@nuist.edu.cn \\ * Correspondence: txchen@nuist.edu.cn (T.C.); carolstt@gmail.com (T.S.); Tel.: +025-58695687 (T.C.)
}

Received: 14 January 2020; Accepted: 19 March 2020; Published: 25 March 2020

\begin{abstract}
The semi-arid and arid drylands of China, which are located in the inland region of Eurasia, have experienced rapid climate change. Some regions in particular, have shown upward trends in the observational records of precipitation. However, there is more to drying and wetting than just changes in precipitation which still have large uncertainties. Coherent results, however, can be obtained, at the regional scale, with the use of multiple indices as shown in the recent literature. We divided the drylands of China into three sub-regions, i.e., a semi-arid (SA), an eastern-arid (EA) and a western-arid (WA) region. Precipitation from the China Meteorological Administration (CMA) and Climatic Research Unit (CRU), statistical and physical drought indices, including the Standardized Precipitation Evapotranspiration Index (SPEI), the Palmer Drought Severity Index (PDSI), self-calibrating PDSI (sc_PDSI), Root zone soil moisture (Root_sm) and Surface soil moisture (Surf_sm) from Global Land Evaporation Amsterdam Model (GLEAM), and Normalized Difference Vegetation Index (NDVI) were used to identify temporal and spatial patterns in drying and wetting. Data were selected from 1982-2012, in line with the availability of the remotely sensed vegetation data. Results show that the drylands of China exhibits a pattern of wetting in the west and drying in the east. The semi-arid region in the east is becoming drier and the drought area is increasing, with the values of CMA_P, CRU_P, PDSI, sc_PDSI, SPEI-01,SPEI-06, SPEI-12, Root_sm, Surf_sm at $-1.064 \mathrm{~mm} \mathrm{yr}^{-1},-0.834 \mathrm{~mm} \mathrm{yr}^{-1},-0.050 \mathrm{yr}^{-1}(p<0.1),-0.174 \mathrm{yr}^{-1}(p<0.1),-0.014 \mathrm{yr}^{-1},-0.06$, $-0.021(p<0.1),-0.257 \times 10^{-3} \mathrm{~m}^{3} \mathrm{~m}^{-3} \mathrm{yr}^{-1},-0.024 \times 10^{-3} \mathrm{~m}^{3} \mathrm{~m}^{-3} \mathrm{yr}^{-1}$, respectively. The arid region generally exhibits a wetting trend, while the area in drought declines only in the western arid region, but not in the eastern arid part. In the semi-arid region, growing season (May to September) NDVI is significantly correlated $(p<0.1)$ with eight out of nine indicators. We show in this study that the semi-arid region needs more study to protect the vegetation ecosystem and the water resources.
\end{abstract}

Keywords: dryland; drought index; drying and wetting trend; vegetation

\section{Introduction}

Drying and wetting patterns due to climate change have an important impact on social development and ecosystems. Therefore, they have always been one of the key issues of climate change. Dozens of drought indices, besides trends in precipitation, have been developed and extensively used in 
various studies [1]; for example, the Palmer Drought Severity Index (PDSI), the self-calibrating variant PDSI (sc_PDSI) [2,3], Standardized Precipitation Index (SPI) [4] and the Standardized Precipitation Evapotranspiration Index (SPEI) [5], etc. However, the assessment of drying and wetting trends at a global scale using the drought indices remains highly controversial. For example, Dai, adopting the PDSI, reported that global droughts are increasing [6]. However, Sheffield et al., also used PDSI, finding no significant drought trends globally [7]. This was mainly due to the calculation of PDSI with two different schemes, i.e., the Thornthwaite method as well as the Penman-Monteith method, were used for the estimation of potential evapotranspiration (PET). The Thornthwaite method [8] easily overestimates the amount of PET, leading to an increase in droughts. The Penman-Monteith method [7,9] is more accurate because it takes into account the dryness of the atmosphere through the vapor pressure deficit. Usually the grass reference method (Food and Agriculture Organization of the United Nations, FAO), a variant of the Penman-Monteith method, is used in PET calculation where both aerodynamic conductance and stomatal conductance are set as constants.

The accuracy and reliability of the calculation of drought indices are still under study, including comparisons between physical drought indices and statistical drought indices $[10,11]$ and the sensitivity of algorithms used in the intermediate process calculation of the drought indices [12]. Although it is difficult to obtain deterministic conclusions at the global scale, consistent conclusions can more likely be obtained at the regional scale. In concert, a satisfactory drought prediction may then be obtained using multivariate drought indices [13]. This paper aims to test that hypothesis and obtain consistent results e.g., [14], in the drylands area of China.

The drylands of China, including the arid and semi-arid areas, is one of the core parts of the drylands of East Asia (the other part is on the Mongolian plateau), experiencing severe climate change and increasing human activities $[15,16]$. Previous studies have shown that the temperature and humidity in the arid regions of northern China have changed drastically, and the regional variations of drying and wetting are large. The warming in the arid regions of northern China is synchronized with global warming, but is also showing a more pronounced trend $[17,18]$. In terms of precipitation, Xinjiang and other places show a significant tendency of wetting [19]. The corresponding changes in temperature and humidity will likely affect the spatial and temporal distribution of vegetation [20]. Changes over the semi-arid areas are more closely related to human activities than over the arid areas due to the relatively dense population and livestock. At the same time, the vulnerability of ecosystems to climate change is increasing [21], making the differential impact of climate change in the region visible and therefore important. The climate change patterns and mechanisms of typical dryland regions have far-reaching implications for the selection of regional sustainable development goals and strategies [22].

This paper will analyze the drying and wetting trend in the drylands of China based on the hypothesis proposed by Chen et al. [14]. The trends of multiple indicators at the regional average and individual grid boxes were both calculated. We then compared and determined whether the results supported the robust conclusion of drying and wetting trends. As ecosystems in drylands are vulnerable to water availability, it is necessary to further clarify which type of dryness indicators the vegetation system is more sensitive to. In these areas, vegetation grows mainly from May to September (M-S). The freezing in winter will limit the application of a drought index due to the simplified water balance processes. Therefore, the variation in vegetation patterns and its correlation with the indicators needs to be further clarified. In this paper, we analyzed the Pearson correlation coefficients between indices and M-S NDVI from previous October to September (O-S) and in the growing season of May to September 


\section{Materials and Methods}

\subsection{Study Area}

The semi-arid and arid drylands of China, as shown in Figure 1, span about $3800 \mathrm{~km}$ along the west-east direction, with the latitudes ranging from N34.40 to N49.85. It is divided into three sub-regions, i.e., the semi-arid (SA), the eastern arid (EA) and the western arid (WA). The boundaries of the drylands and its three sub-regions were extracted from the dataset of eco-geographical regions of China, which was downloaded from the Resource and Environment Data Cloud Platform (http://www.resdc.cn/).

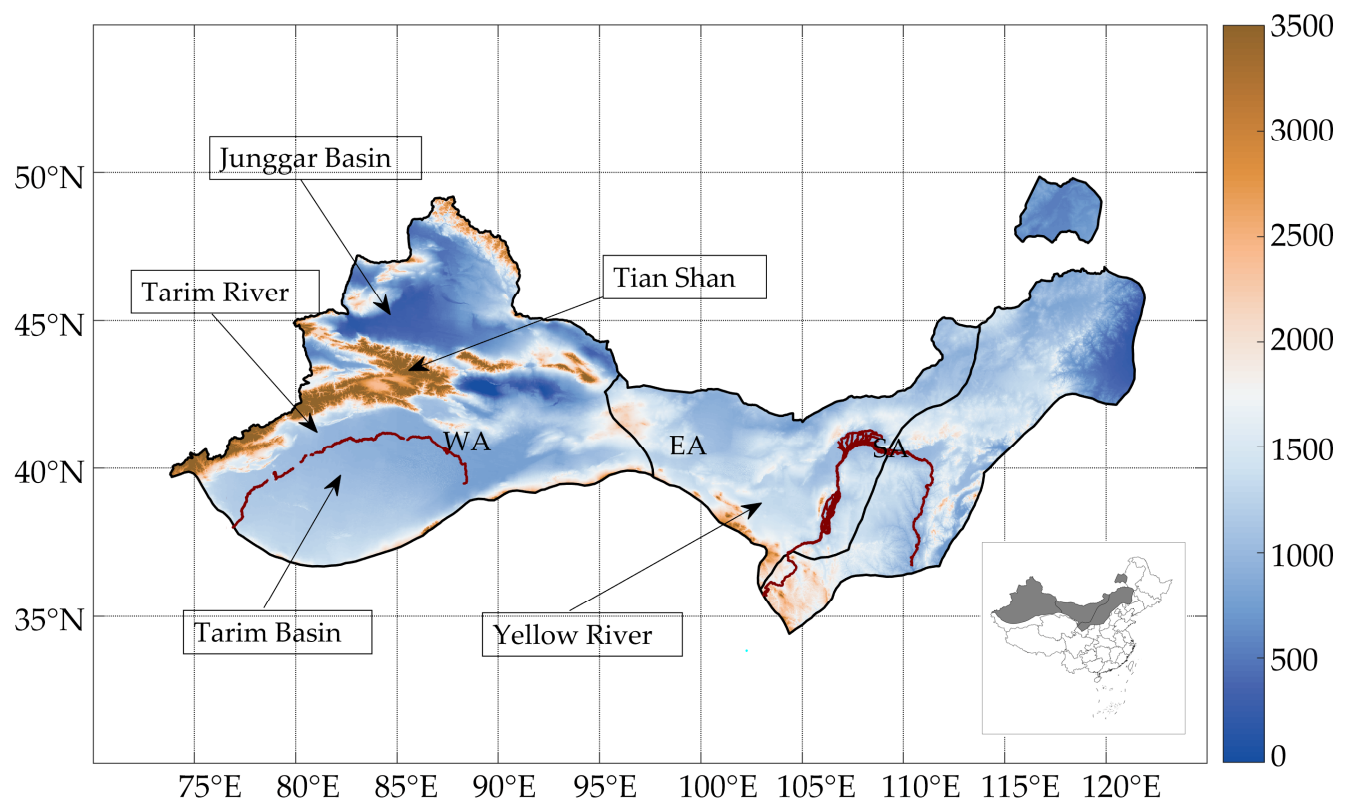

(a)

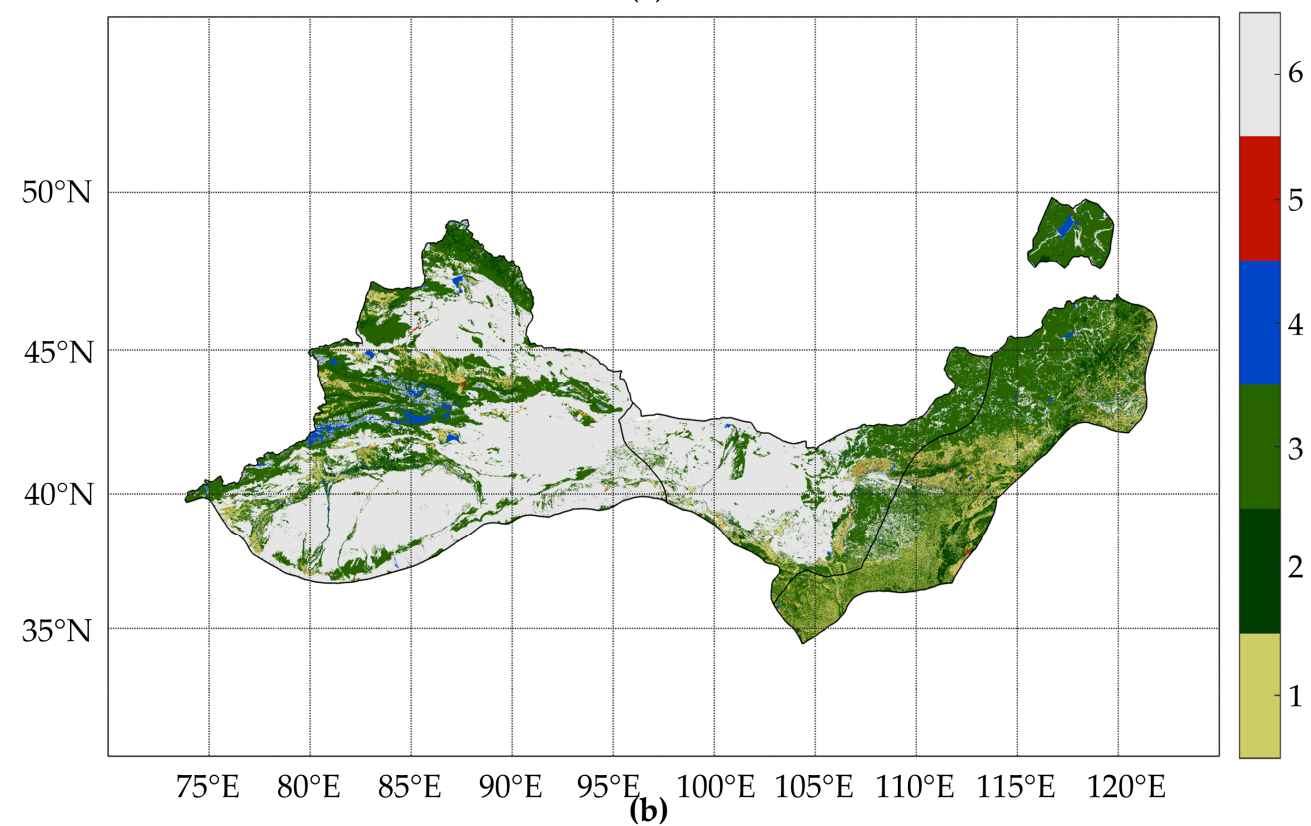

Figure 1. The location of drylands of China. (a) Topography. The DEM (Digital Elevation Model) of GTOP30 data is used; (b) Land use cover. They are: (1) cropland, (2) woodland, (3) grassland, (4) water body, (5) build-up area and (6) unused land. 


\subsection{Land Cover Data}

The land use data was obtained from China's 1:100,000-scale land use status remote sensing monitoring database, including six land cover types and 25 sub-categories. We selected the year 2000 as a reference. The dataset is based on Landsat TM and ETM images, using human-computer interaction interpretation to interpret images that are not covered by Landsat TM images or that cover poor image quality, supplemented with Ambient 1 satellite CCD multispectral data. Unified quality control and integration checks were performed on each database to ensure high quality and consistent interpretation [23-25]. Figure $1 \mathrm{~b}$ and Table 1 show the land cover types. Grasslands and unused land are the main covers in the arid areas, while in the semi-arid areas the land was mainly covered by grassland and farmland. This study area is shaped with basins, mountains and plains, etc.

Table 1. Land cover types of Figure $1 \mathrm{~b}$ and the percentages of each component.

\begin{tabular}{ccc}
\hline Class \# & Class Name & $\%$ \\
\hline 1 & Cropland, including paddy and dry fields & 9.58 \\
2 & Woodland, including natural and economic woodland & 4.00 \\
3 & Grassland with a coverage $>5 \%$ & 36.47 \\
4 & Water body, including natural land waters and land for water & 1.68 \\
5 & conservancy facilities & 0.70 \\
6 & Build-up land & 47.34 \\
\hline
\end{tabular}

\subsection{Meteorological Data}

Precipitation and temperature from the China Meteorological Administration (CMA) and Climatic Research Unit (CRU) are selected. The CMA-precipitation is generated based on more than 2000 observatories in China [26]. Comparatively, the CRU TS3.22 dataset is more widely used [27].

\subsection{Drought Index}

Drought indices are widely used in drying and wetting studies. In this study, besides precipitation, three drought indices were used: SPEI, PDSI, sc_PDSI. SPEI is a statistical drought index which is based on a similar algorithm to that of the original SPI. Therefore, SPEI has a multi-scale characteristic. Unlike SPI, temperature effect is considered in SPEI by calculating the potential evapotranspiration [28]. The first calculation of the times series of the differences between precipitation $(\mathrm{P})$ and potential evapotranspiration (PET) is given as:

$$
D_{j}^{k}=\sum_{i=0}^{k-1}\left(P_{j-i}-P E T_{j-i}\right), j \geq k
$$

where $k$ is the time scale, $D_{j}^{k}$ is the $P-P E T$ difference of month $j$ at the time scale $k$. After that, a three-parameter log-logistic distribution was chosen to model the D series. Finally, SPEI was generated by standardization [16]. In this study, the SPEI v2.3 data (available from http://sac.csic.es/ spei/database.html) was used. Similar to previous studies [29,30], the 1, 6, 12 months scale SPEI were used to analyze the drying and wetting trends in this study.

PDSI is a physical drought index calculated based on a two-layer soil water balance [2]. PDSI combines effects of the water deficit and impacts of the duration to the severity of drought. Firstly, the difference $(d)$ between climatically appropriate for existing conditions (CAFEC) precipitation $\left(p^{\prime}\right)$ and the actual precipitation $(p)$ is calculated. Then, the moisture anomaly index ( $Z$ index) is generated by applying a climatic characteristic coefficient $K$ on $(d)$. Finally, the PDSI value is caculated based on Z index and duration coefficient. The calculation formula is as follows:

$$
d=p-p^{\prime}
$$




$$
\begin{gathered}
K^{\prime}=1.5 \times \log \left[\frac{\overline{P E T}+\bar{R}+\overline{R O}}{(\bar{P}+\bar{L}) \bar{D}}+\frac{2.8}{\bar{D}}\right]+0.5 \\
K=\frac{17.67}{\sum_{1}^{12} \bar{D} K^{\prime}} K^{\prime} \\
Z=K d \\
X_{i}=0.897 X_{i-1}+\frac{Z_{i}}{3}
\end{gathered}
$$

$\overline{P E T}$ is the mean potential evapotranspiration, $\bar{R}$ is the mean recharge moisture, $\overline{R O}$ is the mean runoff, $\bar{P}$ is the mean precipitation, and $\bar{L}$ is the mean moisture loss. $\bar{D}$ is the mean absolute value of $d . k$ is a climatic characteristic coefficient. $Z$ is the moisture anomaly index which is generated by applying $k$ on $d$. The 0.897 and $1 / 3$ are constant coefficients which reflect the influence of previous moisture and month $Z$ index. Meanwhile, the sc_PDSI changes the climatic characteristic coefficient $k$ and the constant coefficient 0.897 and 1/3 in the PDSI based on local historical climatic data for each station or grid. Therefore, sc_PDSI presents better spatial compatibility than PDSI [3,31].

Previous studies have shown that the PET calculation scheme may have a substantial impact on the estimation of PDSI trends. The Penman-Monteith method is generally more accurate than the Thornthwaite method in PET $[6,32,33]$. The full Penman-Monteith equation can be expressed as follows:

$$
\lambda E T=\frac{\Delta\left(R_{n}-G\right)+\rho_{a} c_{p}\left(e_{s}-e_{a}\right) / r_{a}}{\Delta+\gamma\left(1+\frac{r_{s}}{r_{a}}\right)}
$$

where $\lambda$ is the latent heat of vaporization, $E T$ is the evapotranspiration flux described as depth per unit time, $\Delta$ is the slope of the saturation vapor pressure minus temperature, $R_{n}$ is the net radiation flux density at the surface, $G$ is the soil flux, $\rho_{a}$ is the air density, $c_{p}$ is the specific heat of moist air under constant pressure, $e_{S}$ is the saturation vapor pressure at air temperature, $e_{a}$ is the actual vapor pressure of the air, $r_{a}$ is the aerodynamic resistance to turbulent heat and/or vapor transfer from the surface to some $Z$ height above the surface, $\gamma$ is the psychrometric constant, $r_{s}$ is the canopy conductance that describes the water vapor flowing from inside the leaf, vegetation canopy or soil to outside the surface.

Therefore, this paper adopted PDSI and its deformation sc_PDSI with the Penman-Monteith equation for PET estimations [7]. The PDSI and sc_PDSI data used in this study is produced by Sheffield [34].

\subsection{The GLEAM Soil Moisture}

The GLEAM (http://www.gleam.eu/) model is used to calculate the evaporative flux over land with maximize the use of satellite-derived observations [35]. The root-zone soil moisture (Root_sm) and surface soil moisture (Surf_sm) can also be obtained from GLEAM. Because the use of constant parameters in GLEAM, the bare soil, short vegetation and vegetation with a tall canopy was chosen. The global model contains four modules including a separate module of the water budget (rain and snow) over the root-zone. The water balance of three land surface types was calculated separately and each type has a different number of layers. The bare soil has one layer $(0-0.05 \mathrm{~m})$ and short vegetation has the second layer $(0.05-1.00 \mathrm{~m})$. For the vegetation with a tall canopy, two layers $(0.05-1.00 \mathrm{~m}$ and $1.00-2.50 \mathrm{~m})$ were considered. The soil moisture content $(\omega)$ of each layer $(l)$ on a given day $(i)$ is calculated as follows:

$$
\omega_{i}^{(l)}=\omega_{i-1}^{(l)}+\frac{F_{i}^{(l-1)}-E_{i-1}^{(l)}-F_{i}^{(l)}}{\Delta z^{(l)}}
$$


where $F^{(l-1)}$ and $F^{(l)}$ is the downward flux from the above layer, $E^{l}$ denotes the loss of soil water caused by evaporation, $\Delta z^{(l)}$ is the thickness of the layer. $F^{(l)}$ is estimated by formula as follows:

$$
F_{i}^{(l)}=\left(\omega_{i}^{(l)}-\omega_{f c}\right) \Delta z^{(l)}
$$

where $\omega_{f c}$ is the field capacity. Simultaneously, microwave remote sensing datasets of surface soil moisture were used to constrain the uncertainty of the modelled results. Additionally, the Kalman filter assimilation approach was used to correct running water balance estimates at the daily time step.

\subsection{Normalized Difference Vegetation Index (NDVI)}

NDVI data is widely used to describe vegetation conditions; for example, the inter annual changes and spatial patterns [36,37]. In this study, the NDVI data was obtained from the third-generation data of the Global Inventory Monitoring and Modeling System (GIMMS). This NDVI data is aggregated by different AVHRR sensors and considers various detrimental effects such as calibration losses, orbital drift, and volcanic eruptions. The latest version of the GIMMS NDVI dataset covers the time range from July 1981 to December 2015 [38,39]. The equation used is:

$$
N D V I=\frac{(N I R-V I S)}{(N I R+V I S)}
$$

where NIR and VIS indicate spectral reflectance at the near-infrared and visible (red) spectral band range.

\subsection{Statistical Methods}

The least squares linear trend analysis was chosen to calculate the linear trends of precipitation and the drought indices. Simultaneously, the significance of these linear trends was examined by Mann-Kendall trend analysis [40,41]. The Mann-Kendall trend analysis is a nonparametric statistical method. The advantage of this method is that it does not require the data to have a normal distribution. Therefore, this method is widely applied to evaluate changes of trends of meteorological and hydrological time series. In addition, the Pearson correlation coefficients between NDVI and precipitation drought indices were calculated.

\section{Results}

\subsection{Spatial Patterns of Regional Climate and Vegetation}

The annual average patterns of precipitation, temperature and vegetation in the study area from 1982 to 2012 are shown in Figure 2. Generally, both the CMA and CRU datasets show that precipitation decreased from the east to the west, with the lowest precipitation occurring in the desert areas of the western arid region. The western Tianshan Mountains and the Junggar Basin (upper left corner area) are relatively humid in the arid regions. However, CRU precipitation clearly underestimates the wetness of this area (see the circle in Figure 2) compared to CMA records. Specifically, in the Tianshan area, the annual average of the gridded CMA precipitation can reach $400-500 \mathrm{~mm}$ or even more. In contrast, most of the gridded CRU precipitation was less than $300 \mathrm{~mm}$. Moreover, the vegetation condition, as reflected by the NDVI data, further confirmed the above conclusion that the precipitation was underestimated by the CRU dataset. In particular, this can be found in the Tianshan Mountains and its western regions. 

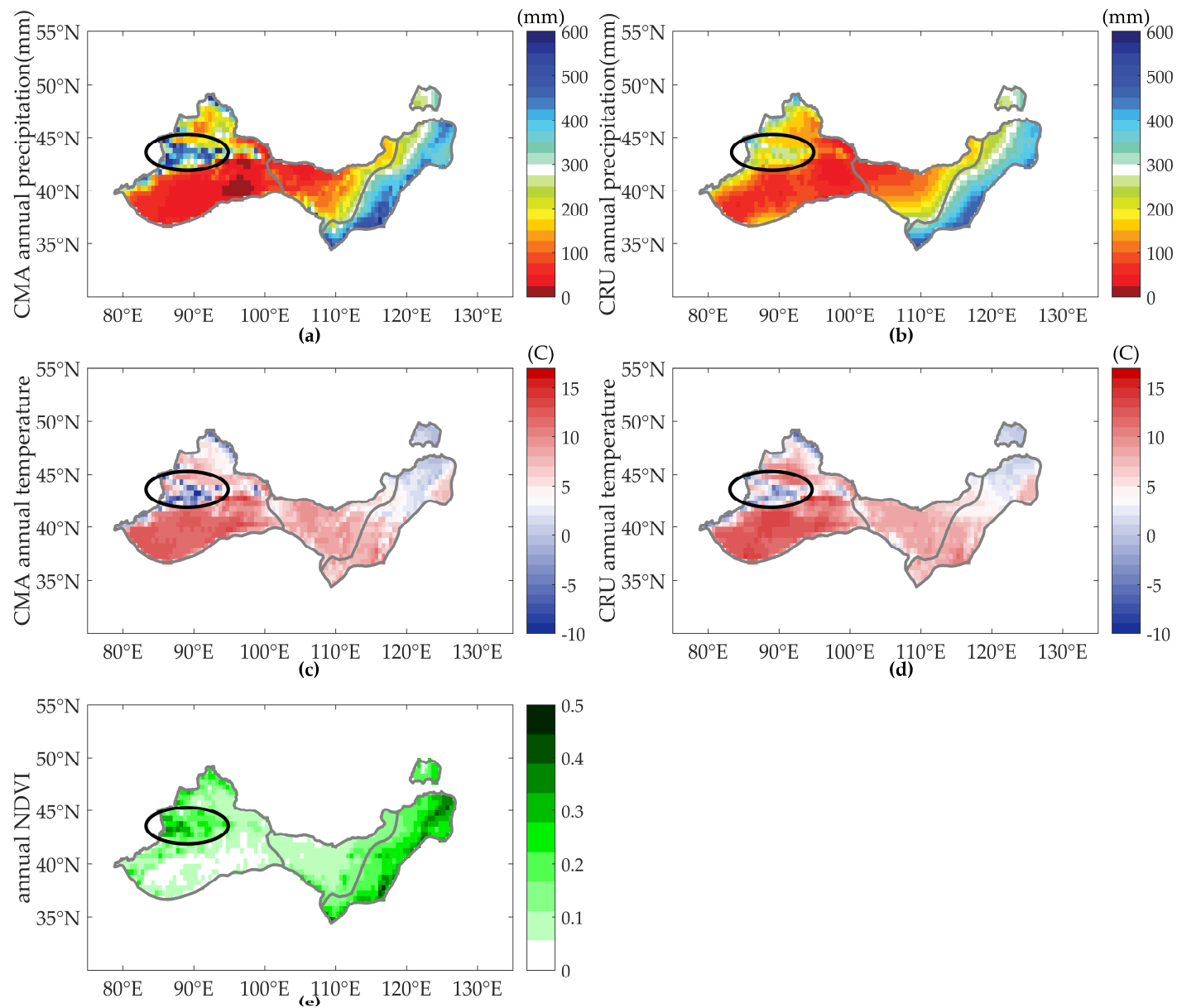

Figure 2. The distribution of the annual averages of the precipitation, temperature and NDVI during 1982-2012 over the drylands. (a,b) Precipitation (mm) records from CMA and CRU 3.22; (c,d) Temperature $\left({ }^{\circ} \mathrm{C}\right.$ ) data from CMA and CRU 3.22; (e) NDVI from NDVI3g. Circled area denotes the western Tianshan Mountains.

In contrast, the annual averaged temperature of CMA and CRU datasets show a better consistency than that recorded for precipitation. The main difference was also found in the Tianshan area. The annual averaged CRU temperature was a litter higher than that of CMA. For the CRU data, a limited number of observations were available in this area for interpolation which makes it difficult to generate accurate temperature reanalysis data. The annual averaged NDVI decreased from the east to the west. The annual averaged NDVI in semi-arid areas is mostly $0.2-0.4$ (75.58\% of the semi-arid area), whereas in the arid region, the annual averaged NDVI values were reduced to about $0-0.2(90.71 \%$ of the arid area).

However, in the Tianshan Mountains and its western areas, the NDVI values were higher, with a magnitude greater than 0.3 ( $1.71 \%$ of the arid area).

\subsection{Regional Averaged Wetting and Drying Trends Calculated by Nine Dryness Indicators}

The drying and wetting trends of dryness indicators were further investigated in the study area as shown in Table 2 and Figure 3. For the whole dryland area, no consistent drying or wetting trend was found among the nine dryness indicators. Specifically, an increasing trend was found among six dryness indicators, i.e., SPEI-01, SPEI-06, Root_sm, Surf_sm, CMA_P and CRU_P. However, a decreasing trend was detected among another 3 dryness indicators, i.e., SPEI-12, PDSI and sc_PDSI. 
Table 2. Linear Trends of nine dryness indicators: precipitation including CMA_P and CRU_P (mm $\left.\mathrm{yr}^{-1}\right)$, PDSI $\left(\mathrm{yr}^{-1}\right)$, sc_PDSI $\left(\mathrm{yr}^{-1}\right)$, SPEI-01 $\left(\mathrm{yr}^{-1}\right)$, SPEI-06 $\left(\mathrm{yr}^{-1}\right)$, SPEI-12 $\left(\mathrm{yr}^{-1}\right)$, Root_sm $\left(10^{-3} \mathrm{~m}^{3}\right.$ $\left.\mathrm{m}^{-3} \mathrm{yr}^{-1}\right)$, Surf_sm $\left(10^{-3} \mathrm{~m}^{3} \mathrm{~m}^{-3} \mathrm{yr}^{-1}\right)$.

\begin{tabular}{|c|c|c|c|c|}
\hline & Dryland & Semi-Arid & Eastern-Arid & Western-Arid \\
\hline \multicolumn{5}{|c|}{ Annual } \\
\hline CMA_P & 0.304 & -1.064 & $0.840 *$ & $0.902 *$ \\
\hline CRU_P & 0.143 & -0.834 & 0.526 & 0.476 \\
\hline PDSI & -0.010 & $-0.050 *$ & 0.006 & 0.002 \\
\hline sc_PDSI & $-0.048 *$ & -0.174 * & 0.002 & 0.008 \\
\hline SPEI-01 & 0.005 & -0.014 & 0.013 & 0.012 \\
\hline SPEI-06 & 0.006 & -0.006 & 0.013 & 0.010 \\
\hline SPEI-12 & -0.002 & $-0.021 *$ & 0.012 & 0.006 \\
\hline Root_sm & 0.119 & -0.257 & $0.266^{*}$ & 0.248 * \\
\hline Surf_sm & $0.332 *$ & -0.024 & $0.472 *$ & 0.359 * \\
\hline \multicolumn{5}{|c|}{ Growing Season } \\
\hline CMA_P & -0.091 & -1.416 & 0.427 & 0.336 \\
\hline CRU_P & -0.169 & -1.111 & 0.200 & 0.013 \\
\hline PDSI & -0.018 & $-0.065^{*}$ & -0.000 & 0.004 \\
\hline sc_PDSI & $-0.051 *$ & -0.178 * & -0.002 & 0.005 \\
\hline SPEI-01 & 0.006 & -0.012 & 0.013 & 0.013 \\
\hline SPEI-06 & -0.001 & -0.010 & -0.000 & 0.003 \\
\hline SPEI-12 & 0.000 & -0.019 & 0.012 & 0.006 \\
\hline Root_sm & 0.001 & -0.359 & 0.138 * & 0.139 * \\
\hline Surf_sm & 0.067 & -0.395 & 0.248 * & 0.221 * \\
\hline
\end{tabular}

* Significant values $(p<0.1)$ are indicated. 0.000 and -0.000 appear because the absolute values are less than 0.0005 .

In contrast, generally coherent results were found over all three sub-regions. Based on the trend analysis values of the nine dryness indicators (CMA_P, CRU_P, PDSI, sc_PDSI, SPEI-01, SPEI-06, SPEI-12, Root_sm and Surf_sm) in Table 2, the following conclusions can be drawn. A decreasing trend, i.e., drying, was found in the semi-arid region. However, an increasing trend, i.e., wetting, was found among all the nine dryness indicators in both the east and west arid regions.

Similar trends of three sub-regions were found by comparing the annual results with the values during the growing season. However, for the entire dryland, both CMA_P and CRU_P exhibited a decreasing trend (Table 2). 


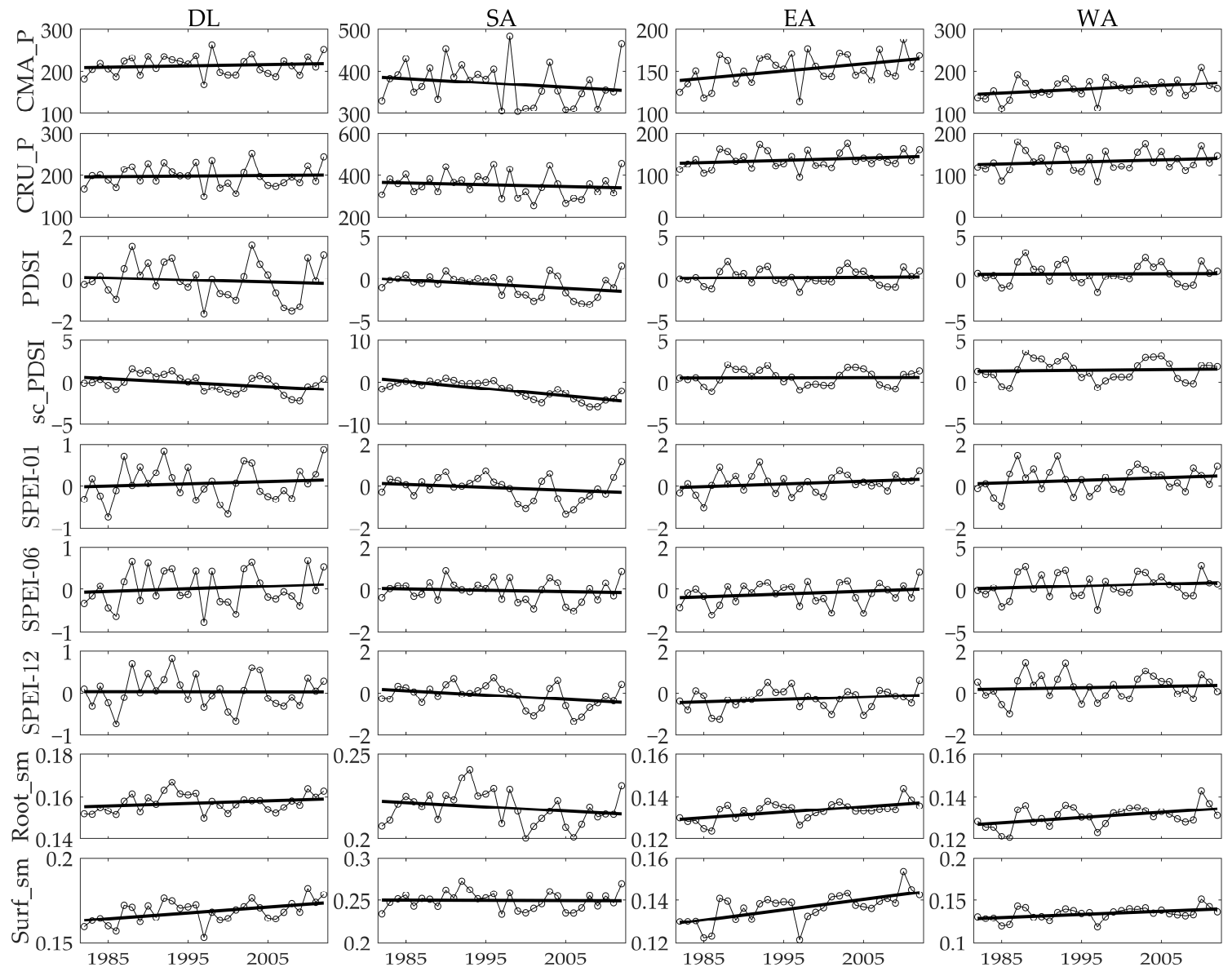

Figure 3. Interannual variation of nine dryness indications: precipitation (mm), PDSI, sc_PDSI, SPEI-01, SPEI-06, SPEI-12, Root_sm $\left(\mathrm{m}^{3} \mathrm{~m}^{-3}\right)$ and Surf_sm $\left(\mathrm{m}^{3} \mathrm{~m}^{-3}\right)$, in drylands and its three sub-regions, during 1982-2012. The solid lines indicate the linear fits during 1982-2012.

\subsection{Spatial Patterns of Drying and Wetting Trends by Means of Nine Dryness Indicators}

The spatial distribution of the trends based on the indices at the grid scale is shown in Figure 4. These indices exhibit generally coherent spatial patterns. Drying trends dominate the semi-arid region, and the drying range indicated by CMA_P is slightly smaller than CRU_P (Figure 4a,b). The Surf_sm also represents a smaller drying range than Root_sm which is significant to the ecosystem. The region with the most severe dryness is in the eastern corner. This area is a desert grassland-shrubland transition zone. Evidently, all the indices indicated a larger drying trend than other regions. In the eastern arid area, wetting trends contribute most to areas indicated by these indices except sc_PDSI. Over the western arid region, both drying and wetting areas are found. Referring to the land use and elevation distribution indicated in Figure 1, it can be found that the drying trends were mainly located in the desert area, such as the Taklimakan desert and western Gobi desert and the wetting trends were close to the Tianshan Mountains and Altai Mountains. 


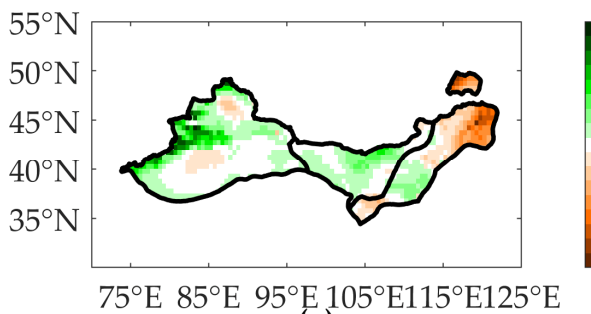

(a)
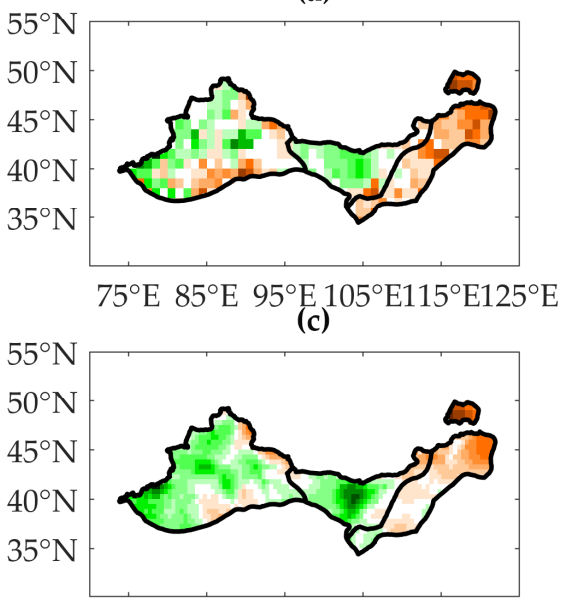

$75^{\circ} \mathrm{E} 85^{\circ} \mathrm{E} 95^{\circ} \mathrm{E} 105^{\circ} \mathrm{E} 115^{\circ} \mathrm{E} 125^{\circ} \mathrm{E}$

(e)

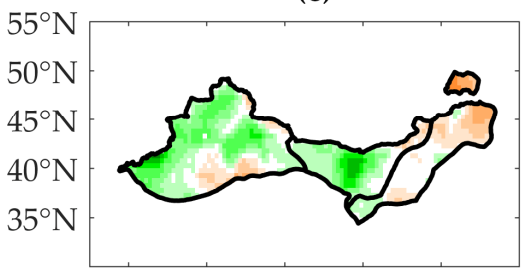

$75^{\circ} \mathrm{E} 85^{\circ} \mathrm{E} 95^{\circ} \mathrm{E} 105^{\circ} \mathrm{E} 115^{\circ} \mathrm{E} 125^{\circ} \mathrm{E}$ (g)

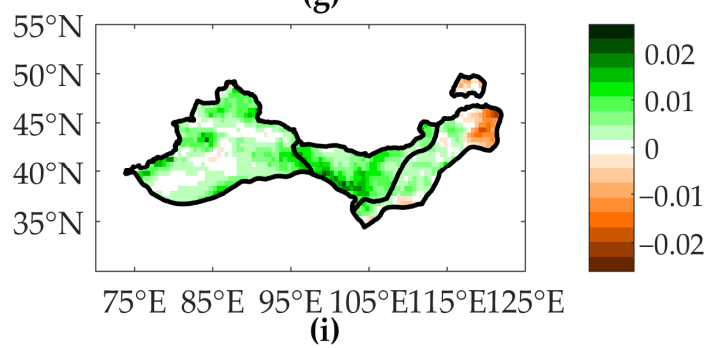

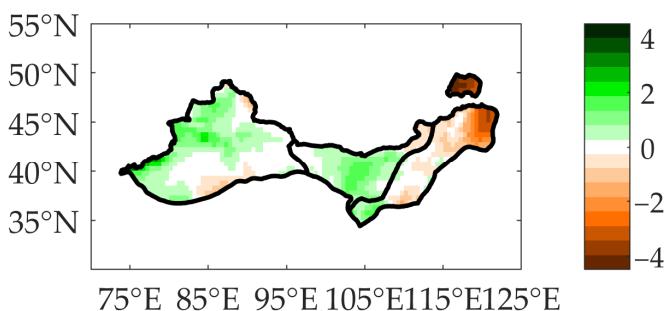

(b)

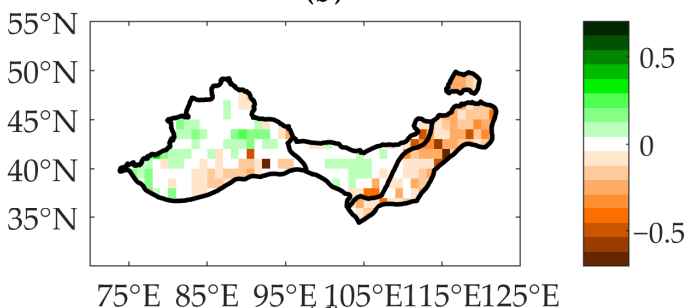

(d)

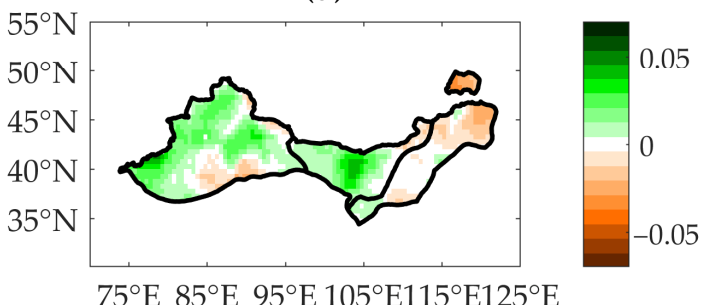

(f)

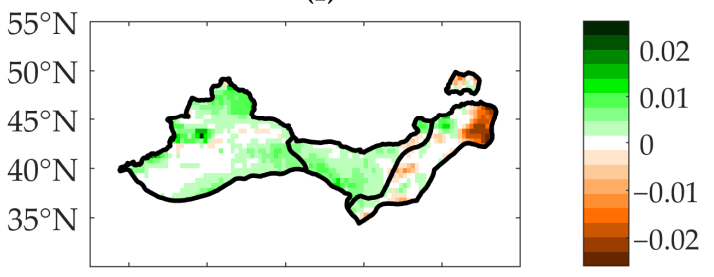

$75^{\circ} \mathrm{E} 85^{\circ} \mathrm{E} 95^{\circ} \mathrm{E} 105^{\circ} \mathrm{E} 115^{\circ} \mathrm{E} 125^{\circ} \mathrm{E}$

(h)

Figure 4. The spatial distribution of annual trends at the grid scale. (a) CMA_P $\left(\mathrm{mm} \mathrm{yr}^{-1}\right)$; (b) CRU_P $\left(\mathrm{mm} \mathrm{yr}^{-1}\right)$; (c) PDSI $\left(\mathrm{yr}^{-1}\right)$; (d) sc_PDSI $\left(\mathrm{yr}^{-1}\right)$; (e) SPEI-01 $\left(\mathrm{yr}^{-1}\right)$; (f) SPEI-06 $\left(\mathrm{yr}^{-1}\right)$; (g) SPEI-12 $\left(\mathrm{yr}^{-1}\right)$, (h) Root_sm $\left(\mathrm{m}^{3} \mathrm{~m}^{-3} \mathrm{yr}^{-1}\right)$, (i) Surf_sm $\left(\mathrm{m}^{3} \mathrm{~m}^{-3} \mathrm{yr}^{-1}\right)$ during 1982-2012. The solid lines indicate the boundaries of the regions used in this study.

\subsection{Drought Area Variations}

Figure 5 demonstrates the regional average time series of the area in drought across each region based on SPEI-01, PDSI, and sc_PDSI. The interannual variation of the area in drought demonstrated by these three indices is generally coherent over the whole dryland and three sub-regions. A feature in the temporal patterns is that SPEI-01 changed ahead a few months of the PDSI and sc_PDSI. Based on the maximum correlation coefficient analysis, the typical time of lag is three months. Although the drylands did not show a very typical increase or decrease in drought, the drought changes more obviously in the three sub-regions. Especially in the semi-arid region, all three indicators showed significant increases in the area in drought during the second half of the study period. Specifically, 
from $1982-1996$ to $1997-2012$, the average area in drought is $5.73 \%$ to $16.37 \%$ for SPEI-01, $13.80 \%$ to $38.82 \%$ for PDSI, and $19.99 \%$ to $68.04 \%$ for sc_PDSI, respectively.
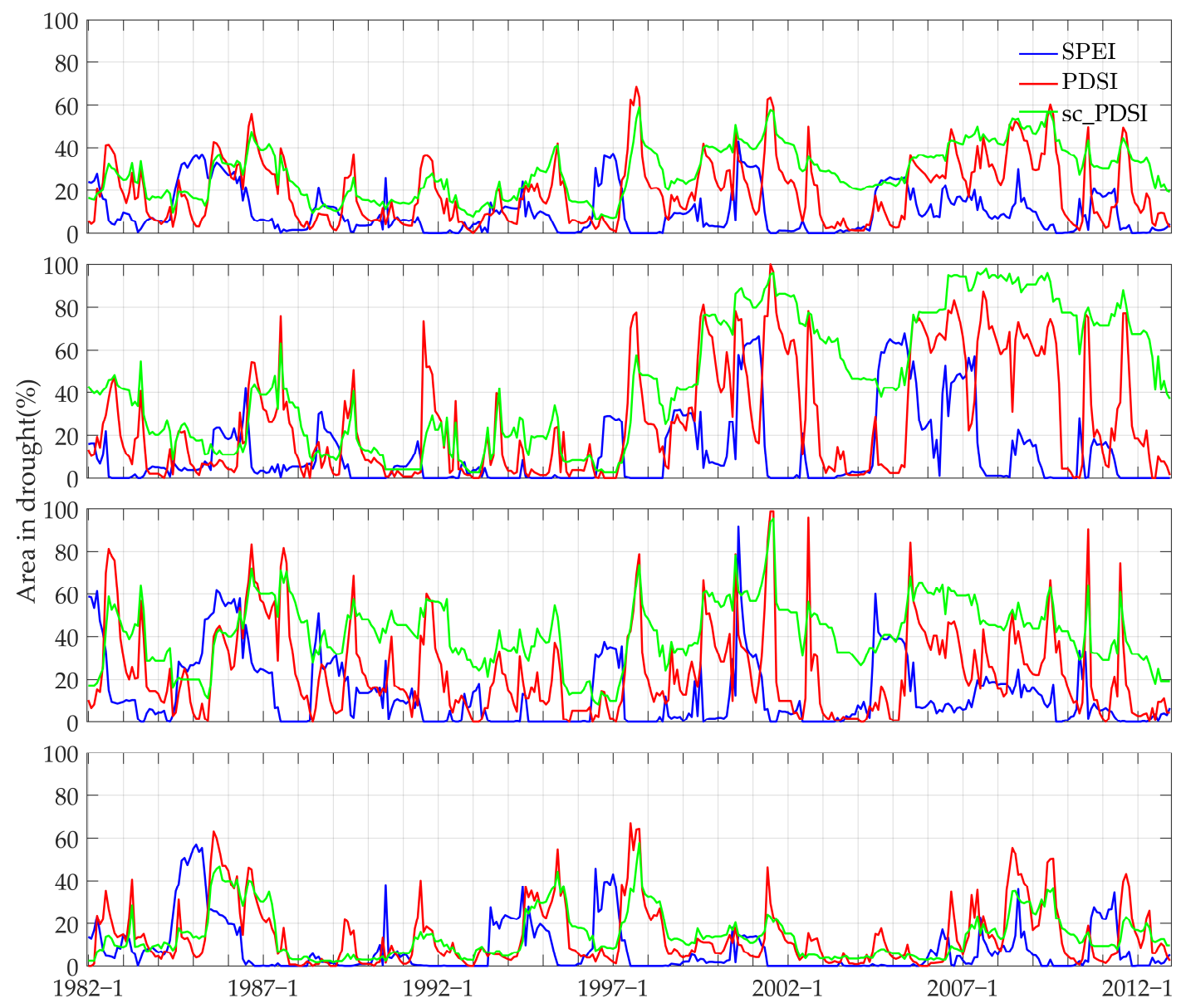

Figure 5. Time series of percentage regional averaged areas in drought of the whole dryland (\%) based on SPEI-01, PDSI, sc_PDSI during 1982-2012. The drought areas are defined locally when SPEI-01 (Blue Lines) is below -1.5; PDSI (Red Lines), sc_PDSI (Green Lines) is below -2. (a) The whole study area; (b) The semi-arid area; (c) The east-arid area; (d) The west-arid area.

There is no particular trend change for the eastern arid region, although there are some years of frequent droughts like the year of 2001. For the western arid region, the area of drought has slightly declined. From 1982-1998 and 1999-2012, the average area in drought is $8.95 \%$ to $5.20 \%$ for SPEI-01, $14.28 \%$ to $13.52 \%$ for PDSI, and $14.76 \%$ to $12.79 \%$ for sc_PDSI, respectively.

\subsection{NDVI Co-Variations}

Usually, water availability is the primary constraint on vegetation growth over drylands and precipitation; drought index and soil moisture are widely used in the studies of water related vegetation dynamics. Here we investigated the covariations of vegetation and water by examining the correlation coefficients $(r)$ between M-S NDVI and these dryness indicators based on time series of O-S and M-S. The regional average and gridded results are shown in Table 3 and Figure 6. 
Table 3. Correlation coefficients between M-S NDVI and the nine dryness indicators during M-S and O-S.

\begin{tabular}{|c|c|c|c|c|}
\hline & Dryland & Semi-Arid & Eastern-Arid & Western-Arid \\
\hline \multicolumn{5}{|c|}{ O-S } \\
\hline CMA_P & 0.624 * & 0.651 * & 0.371 * & $0.665^{*}$ \\
\hline CRU_P & 0.549 * & 0.621 * & 0.264 & $0.523 *$ \\
\hline PDSI & $0.369 *$ & $0.463 *$ & 0.058 & $0.467 *$ \\
\hline Sc_PDSI & 0.055 & 0.096 & -0.300 & $0.470 *$ \\
\hline SPEI-01 & 0.339 * & 0.449 * & 0.128 & 0.222 \\
\hline SPEI-06 & $0.621 *$ & 0.681 * & 0.361 * & 0.589 * \\
\hline SPEI-12 & 0.475 * & $0.463 *$ & 0.200 & $0.595 *$ \\
\hline Surf_sm & $0.572 *$ & $0.575^{*}$ & 0.501 * & 0.577 * \\
\hline Root_sm & 0.419 * & 0.397 * & 0.338 * & $0.581 *$ \\
\hline \multicolumn{5}{|c|}{ Growing Season (M-S) } \\
\hline CMA_P & $0.558 *$ & 0.636 * & 0.389 * & 0.547 * \\
\hline CRU_P & 0.521 * & $0.646^{*}$ & 0.292 & $0.316^{*}$ \\
\hline PDSI & 0.418 * & $0.552 *$ & 0.137 & $0.431 *$ \\
\hline sc_PDSI & 0.121 & 0.167 & -0.197 & $0.466^{*}$ \\
\hline SPEI-01 & 0.181 & $0.316^{*}$ & -0.005 & 0.063 \\
\hline SPEI-06 & 0.539 * & 0.659 * & 0.267 & $0.476^{*}$ \\
\hline SPEI-12 & 0.552 * & 0.593 * & 0.286 & 0.585 * \\
\hline Surf_sm & 0.537 * & 0.598 * & 0.371 * & 0.634 * \\
\hline Root_sm & $0.585^{*}$ & $0.627^{*}$ & $0.406^{*}$ & $0.696^{*}$ \\
\hline
\end{tabular}

* Significant values $(p<0.1)$ are indicated.

High correlations between NDVI and the multiple dryness indicators including precipitation, drought indices and soil moisture, are expected. It can be seen that for the regional averages, the highest positive correlations was found between NDVI and precipitation as well as the soil moisture, that is, the CMA_P, Root_sm and Surf_sm (Table 3) during M-S and O-S periods. However, in the western arid region, the correlations between NDVI and the dryness indicators, except the Root_sm and Surf_sm, during the growing season were lower than during O-S. Consistently, the CMA_P of growing season was also lower than the time range of O-S for the eastern-arid region. The SPEI-06 correlated higher with NDVI than SPEI-01 and SPEI-12 in the semi-arid region. Seeing the spatial pattern, $86.731 \%$ grids exhibited significant positive correlations between CMA_P and NDVI $(p<0.1)$. However, the correlation between CRU_P and NDVI is smaller than that between CMA_P and NDVI (Table 2 and Figure 6b), particularly over the western arid region. Although the PDSI and sc_PDSI all used the CRU precipitation as input, the correlation between NDVI and sc_PDSI was much lower than that between PDSI and NDVI over both region average and spatial patterns (Table 3, Figure 6), especially over the semi-arid region. The grids of positive correlation were only $39.735 \%$ for sc_PDSI over the semi-arid regions. As to the SPEI-01, SPEI-06 and SPEI-12, they had the similar spatial distribution (Figure $6 \mathrm{e}-\mathrm{g}$ ) with $56.796 \%, 70.227 \%$ and $42.071 \%$ grids indicating a positive correlation, which was significant $(p<0.1)$. The Root_sm had a higher positive correlation with NDVI than CMA_P over the eastern and western arid regions during the growing season (Table 3) and the Root_sm was much lower than O-S CMA_P. 


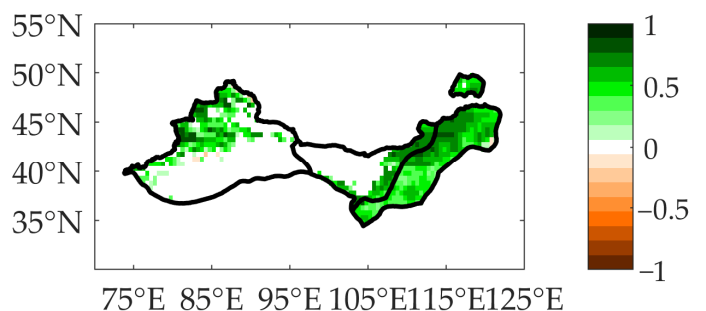

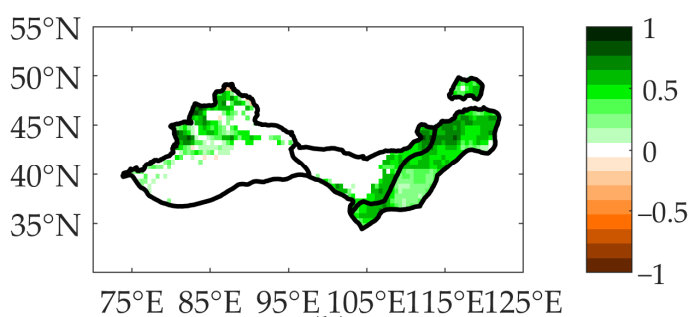

(b)

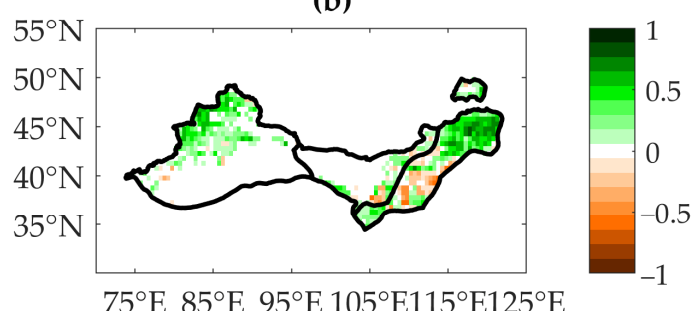

(d)

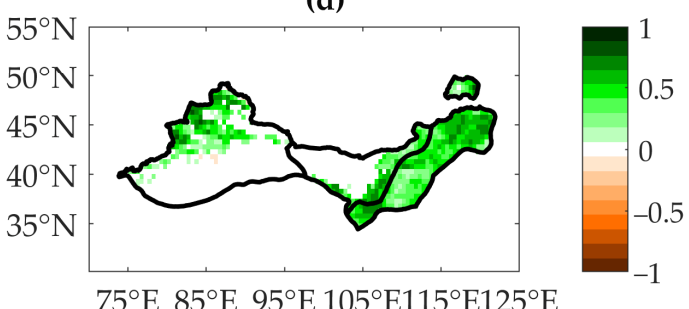

(f)

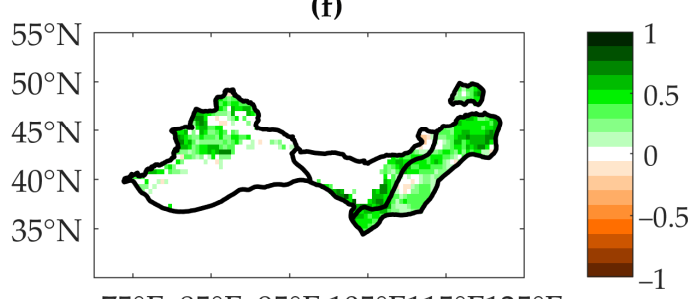

(h)

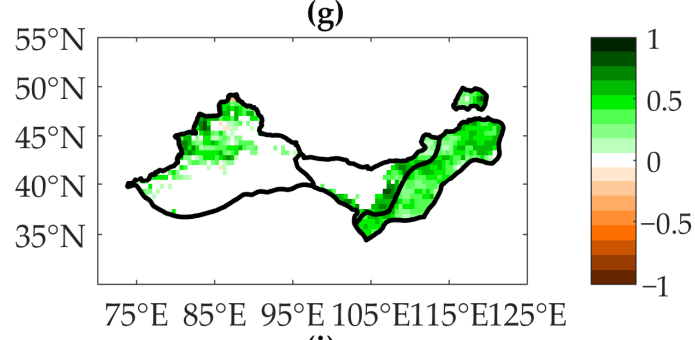

(i)

Figure 6. The correlation between M-S NDVI and nine O-S dryness indicators. In the study area, the max NDVI of each grid lower than 0.2 was not be used. (a) CMA_P; (b) CRU_P; (c) PDSI; (d) Sc_PDSI; (e) SPEI-01; (f) SPEI-06; (g) SPEI-12; (h) Root_sm; (i) Surf_sm.

\section{Discussion}

In this study we evaluated drying and wetting trends over China's drylands based on multiple sets of indicators. Two sets of precipitation were used, the CMA and CRU precipitation. For the calculation of SPEI and PDSI drought indices, the CRU precipitation was used rather than the CMA precipitation because of computational limitations and because it is widely used. The correlations are shown in Table 4. The precipitation of CMA and CRU had similar correlations with other dryness indicators in the eastern-arid and western-arid areas. However, in semi-arid regions, the correlation between CRU precipitation and other dryness indicators was better than that of CMA precipitation with drought indices. This is largely a result of the fact that the drought indices were calculated with the CRU precipitation rather than the CMA set. 
Table 4. The interannual variation of correlations among multiple dryness indicators in three sub-regions of the drylands of China.

\begin{tabular}{|c|c|c|c|c|c|c|c|}
\hline & CMA_P & CRU_P & SPEI-01 & PDSI & sc_PDSI & Root_sm & Surf_sm \\
\hline \multicolumn{8}{|c|}{ Semi-Arid } \\
\hline CMA_P & 1.000 & $0.897 *$ & $0.635 *$ & $0.752 *$ & 0.477 * & 0.740 * & 0.849 * \\
\hline CRU_P & $0.897 *$ & 1.000 & $0.676^{*}$ & $0.809^{*}$ & 0.443 * & 0.649 * & $0.806^{*}$ \\
\hline SPEI-01 & $0.635 *$ & $0.676^{*}$ & 1.000 & 0.653 * & 0.424 * & 0.537 * & 0.613 * \\
\hline PDSI & $0.752 *$ & 0.809 * & 0.653 * & 1.000 & 0.722 * & 0.669 * & 0.702 * \\
\hline sc_PDSI & $0.477 *$ & 0.443 * & $0.424 *$ & $0.722 *$ & 1.000 & 0.584 * & 0.360 * \\
\hline Root_sm & 0.740 * & $0.649 *$ & $0.537 *$ & 0.669 * & $0.584^{*}$ & 1.000 & $0.852 *$ \\
\hline Surf_sm & $0.849 *$ & $0.806^{*}$ & $0.613 *$ & $0.702 *$ & 0.360 * & $0.852 *$ & 1.000 \\
\hline \multicolumn{8}{|c|}{ Eastern-Arid } \\
\hline CMA_P & 1.000 & $0.862 *$ & $0.407 *$ & $0.621 *$ & 0.394 * & $0.757 *$ & 0.799 * \\
\hline CRU_P & $0.862 *$ & 1.000 & $0.568 *$ & $0.818^{*}$ & 0.604 * & 0.598 * & $0.673 *$ \\
\hline SPEI-01 & $0.407 *$ & 0.568 * & 1.000 & 0.419 * & $0.315^{*}$ & 0.373 * & 0.430 * \\
\hline PDSI & $0.621 *$ & $0.818^{*}$ & $0.419 *$ & 1.000 & $0.885^{*}$ & 0.590 * & 0.588 * \\
\hline sc_PDSI & 0.394 * & 0.604 * & $0.315^{*}$ & $0.885^{*}$ & 1.000 & $0.475^{*}$ & 0.433 * \\
\hline Root_sm & 0.757 * & 0.598 * & 0.373 * & 0.590 * & 0.475 * & 1.000 & 0.964 * \\
\hline Surf_sm & $0.799 *$ & 0.673 * & 0.430 * & $0.588^{*}$ & 0.433 * & 0.964 * & 1.000 \\
\hline \multicolumn{8}{|c|}{ Western-arid } \\
\hline CMA_P & 1.000 & 0.853 * & $0.418^{*}$ & $0.655^{*}$ & 0.428 * & 0.774 * & $0.832 *$ \\
\hline CRU_P & $0.853 *$ & 1.000 & $0.601 *$ & $0.848^{*}$ & 0.628 * & $0.617^{*}$ & $0.705^{*}$ \\
\hline SPEI-01 & 0.418 * & $0.601 *$ & 1.000 & 0.450 * & $0.350 *$ & 0.284 & $0.360 *$ \\
\hline PDSI & $0.655 *$ & $0.848^{*}$ & $0.450 *$ & 1.000 & 0.881 * & $0.688^{*}$ & $0.716^{*}$ \\
\hline sc_PDSI & $0.428 *$ & 0.628 * & $0.350 *$ & 0.881 * & 1.000 & $0.586^{*}$ & 0.558 * \\
\hline Root_sm & 0.774 * & 0.617 * & 0.284 & 0.688 * & $0.586^{*}$ & 1.000 & 0.967 * \\
\hline Surf_sm & $0.832 *$ & $0.705^{*}$ & $0.360 *$ & $0.716^{*}$ & 0.558 * & 0.967 * & 1.000 \\
\hline
\end{tabular}

Here, significant differences between CMA and CRU in precipitation and temperature data from annual average trends and spatial patterns were detected. One reason is that the CMA dataset is more detailed in the Tianshan Mountains, and the other reason is that the mean estimates are significantly larger than the CRU in the multi-year trend. Thus, in this study, all the adopted drought indices including SPEI, PDSI and sc_PDSI were calculated based on CRU precipitation. However, as the CMA precipitation product is more accurate than CRU in terms of the number of observations, it is necessary to apply the CMA precipitation for drought indices calculation in future studies within the same topic.

Based on the annual trends of various indices, spatial distribution and changes in the dry areas, we have obtained consistent conclusions to the aggravation of drought in semi-arid areas. In contrast, the eastern-arid and western-arid areas became more wet with dry areas decreasing.

Another interesting finding is that the NDVI time series correlated more with the precipitation (both CMA and CRU) than with the drought indices such as SPEI-01, SPEI-06, SPEI-12, PDSI and sc_PDSI in both regional averaged and gridded results. This is unexpected as one would expect the NDVI to be better correlated with drought indices that express something closer to water availability than just precipitation. Therefore, drought indices are generally regarded as the more appropriate indicator for describing the water conditions rather than precipitation. This is in contrast to previous studies that showed that antecedent precipitation was a significant factor to the vegetation growth in the growing season $[42,43]$. Above all, the application of drought indices in the study of vegetation dynamics may need further evaluations in this region. For instance, the use of the effective drought index (EDI) and standardized evapotranspiration deficit (SEDI) [44,45], which can evaluate the available water resources and detect the response of vegetation to drought at a biological time scale, can be explored in further research. 


\section{Conclusions}

In this study, the drying and wetting trends of the drylands of China and its three sub-regions, i.e., semi-arid, east arid and west arid areas, were investigated by means of nine dryness indicators, including two precipitation indicators as CMA_P and CRU_P, and seven statistical and physical drought indices as SPEI_01, SPEI_06, SPEI-12, PDSI and sc_PDSI, as well as two soil moisture indicators, i.e., root zone soil moisture (Root_sm) and surface soil moisture (Surf_sm), during 1982-2012. These dryness indicators were selected based on Chen's hypothesis that robust conclusions can be obtained by using multiple and sophisticated indices at the regional scales [14]. On the whole, the drylands show a pattern of wetting in the west and drying in the east. Locally, in the sub-regions, drying trends are found in the semi-arid region in the east with the drought area significantly expanded, whereas a wetting trend was detected in the arid region, with the drought area decreasing in the west of this region but not in the eastern part.

The covariations between vegetation and water condition were also evaluated by the correlation coefficients between NDVI and each of the dryness indicators. Precipitation (both CMA and CRU sets) and soil moisture, showed significant correlation values at both regional and grid scales. This implies that vegetation pattern is mainly determined by precipitation and soil moisture. Due to the fragile vegetation ecosystem in the arid regions of northern China, it is important to select appropriate indicators to reflect the water condition for the vegetation. Furthermore, further evaluation should be performed on the rationale of applying drought indices as dryness indicators in the study of vegetation dynamics. Critically important, the results of this paper emphasized that more attention should be paid to the semi-arid region to protect the vegetation ecosystem and the water resources.

The difference between CMA and CRU records of precipitation was also quite large in the western arid region. Regarding to the vegetation spatial pattern related, it was shown that the CMA precipitation was more reliable than CRU precipitation in terms of its spatial distribution. This also implies that careful investigation of using drought indices, calculated based on CMA precipitation, for the vegetation dynamics study, is required in further research.

Author Contributions: T.C. and T.S. designed the study. T.C. and C.L collected the data. C.L. performed the analysis. T.C., T.S. and H.D. wrote the first draft. C.L., T.C., H.D., T.S., X.W., J.X. and D.F.T.H. contributed to the interpretation of the results and jointly revised the manuscript. All authors have read and agreed to the published version of the manuscript.

Funding: This research received no external funding.

Acknowledgments: This research is supported by the National Key R\&D Program of China (NO. 2017YFB0504000), the National Natural Science Foundation of China (NO. 31570464).

Conflicts of Interest: The authors declare no conflict of interest.

\section{References}

1. Heim, R.R. A review of twentieth-century drought indices used in the United States. Bull. Am. Meteorol. Soc. 2002, 83, 1149-1165. [CrossRef]

2. Palmer, W.C. Meteorological Drought; United States Department of Commerce: Washington, DC, USA, 1965; p. 58.

3. Wells, N.; Goddard, S.; Hayes, M.J. A self-calibrating Palmer drought severity index. J. Clim. 2004, 17, 2335-2351. [CrossRef]

4. McKee, T.B.; Doesken, N.J.; Kleist, J. The Relationship of Drought Frequency and Duration to Time Scales. In Proceedings of the 8th Conference on Applied Climatology, Anaheim, CA, USA, 17-22 January 1993; pp. 179-186.

5. Vicente-Serrano, S.M.; Beguería, S.; López-Moreno, J.I. A multiscalar drought index sensitive to global warming: The standardized precipitation evapotranspiration index. J. Clim. 2010, 23, 1696-1718. [CrossRef]

6. Dai, A.G. Increasing drought under global warming in observations and models. Nat. Clim. Chang. 2013, 3, 52. [CrossRef] 
7. Sheffield, J.; Wood, E.F.; Roderick, M.L. Little change in global drought over the past 60 years. Nature 2012, 491, 435. [CrossRef] [PubMed]

8. Thornthwaite, C.W. An approach toward a rational classification of climate. Geogr. Rev. 1948, 38, 55-94. [CrossRef]

9. Monteith, J.L. Evaporation and environment. Symp. Soc. Exp. Biol. 1965, 19, 205-234. [PubMed]

10. Dai, A.G. Characteristics and trends in various forms of the Palmer Drought Severity Index during 1900-2008. J. Geophys. Res. 2011, 116, D12115. [CrossRef]

11. Vicente-Serrano, S.M.; Beguería, S.; López-Moreno, J.I. Comment on "Characteristics and trends in various forms of the Palmer Drought Severity Index (PDSI) during 1900-2008" by Aiguo Dai. J. Geophys. Res. 2011, 116, D19112. [CrossRef]

12. Zhang, J.; Sun, F.; Xu, J.; Chen, Y.; Sang, Y.F.; Liu, C. Dependence of trends in and sensitivity of drought over China (1961-2013) on potential evaporation model. Geophys. Res. Lett. 2016, 43, 206-213. [CrossRef]

13. Hao, Z.; Hao, F.; Singh, V.P. A general framework for multivariate multi-index drought prediction based on Multivariate Ensemble Streamflow Prediction (MESP). J. Hydrol. 2016, 539, 1-10. [CrossRef]

14. Chen, T.; Zhang, H.; Chen, X.; Hagan, D.F.; Wang, G.; Gao, Z.; Shi, T. Robust drying and wetting trends found in regions over China based on Köppen climate classifications. J. Geophys. Res. Atmos. 2017, 122, 4228-4237. [CrossRef]

15. Ma, Z. The interdecadal dry/wet trend and shift of North China and their relationship to the Pacific Decadal Oscillation (PDO). Chin. Sci. Bull. 2007, 52, 2130-2139. [CrossRef]

16. Qi, J.G.; Chen, J.Q.; Wan, S.Q.; Ai, L.K. Understanding the coupled natural and human systems in DrylandsEast. Asia. Environ. Res. Lett. 2012, 7, 015202. [CrossRef]

17. Qin, D.; Ding, Y.; Su, J.; Ren, J.; Wang, S.; Wu, R.; Yang, X.; Wang, S.; Liu, S.; Dong, G. Assessment of Climate and Environment Changes in China (I): Climate and environment changes in China and their projection. Adv. Clim. Chang. Res. 2005, 1, 6-11.

18. Huang, J.; Yu, H.; Guan, X. Accelerated dryland expansion under climate change. Nat. Clim. Chang. 2016, 6, 166-171. [CrossRef]

19. Shi, Y.; Shen, Y.; Kang, E.; Li, D.; Ding, Y.; Zhang, G.; Hu, R.J. Recent and future climate change in northwest China. Clim. Chang. 2007, 80, 379-393. [CrossRef]

20. Chen, T.; Van der Werf, G.R.; De Jeu, R.A.; Wang, G.; Dolman, A.J. A global analysis of the impact of drought on net primary productivity. Hydrol. Earth Syst. Sci. 2013, 17, 3885-3894. [CrossRef]

21. Zhou, G.; He, Q. Advance in the Study on Vulnerability Evaluation and Adaptation Management of Terrestrial Ecosystems. China Basic Sci. 2015, 17, 26-31.

22. Huang, J.; Ji, M.; Liu, Y.; Zhang, L.; Gong, D. An overview of arid and semi-arid climate change. Adv. Clim. Chang. Res. 2013, 9, 9-14. [CrossRef]

23. Liu, J.; Liu, M.; Zhuang, D.; Zhang, Z.; Deng, X. Study on spatial pattern of land-use change in China during 1995-2000. Sci. China Ser. D 2003, 46, 373-384.

24. Liu, J.; Zhang, Z.; Zhuang, D.F.; Wang, Y.; Zhou, W.; Zhang, S.; Li, R.; Jiang, N.; Wu, S. A study on the spatial-temporal dynamic changes of land-use and driving forces analyses of China in the 1990s. Geogr. Res. 2003, 22, 1-12. [CrossRef]

25. Liu, J.; Zhang, Z.; Xu, X.; Kuang, W.; Zhou, W.; Zhang, S.; Li, R.; Yan, C.; Yu, D.; Wu, S. Spatial patterns and driving forces of land use change in China during the early 21st century. J. Geogr. Sci. 2010, 20, 483-494. [CrossRef]

26. Xu, Y.; Gao, X.; Shen, Y.; Xu, C.; Shi, Y.; Giorgi, F. A daily temperature dataset over China and its application in validating a RCM simulation. Adv. Atmos. Sci. 2009, 26, 763-772. [CrossRef]

27. Zhao, T.; Fu, C. Comparison of products from ERA-40, NCEP-2, and CRU with station data for summer precipitation over China. Adv. Atmos. Sci. 2006, 23, 593-604. [CrossRef]

28. Vicente-Serrano, S.; Beguería, S.; Lorenzo-Lacruz, J.; Camarero, J.; López-Moreno, J.I.; Azorin-Molina, C.; Revuelto, J.; Morán-Tejeda, E.; Sanchez-Lorenzo, A. Performance of Drought Indices for Ecological, Agricultural, and Hydrological Applications. Earth Interact. 2012, 16, 1-27. [CrossRef]

29. Paulo, A.A.; Rosa, R.D.; Pereira, L.S. Climate trends and behaviour of drought indices based on precipitation and evapotranspiration in Portugal. Nat. Hazards Earth Syst. Sci. 2012, 12, 1481-1491. [CrossRef]

30. Wang, W.; Zhu, Y.; Xu, R.; Liu, J. Drought severity change in China during 1961-2012 indicated by SPI and SPEI. Nat. Hazards Earth Syst. Sci. 2015, 75, 2437-2451. [CrossRef] 
31. Dai, A. Drought under global warming: A review. Wiley Interdiscip. Rev. Clim. Chang. 2011, 2, 45-65. [CrossRef]

32. Beguería, S.; Vicente-Serrano, S.M.; Reig, F.; Latorre, B. Standardized precipitation evapotranspiration index (SPEI) revisited: Parameter fitting, evapotranspiration models, tools, datasets and drought monitoring. Int. J. Climatol. 2014, 34, 3001-3023. [CrossRef]

33. Ficklin, D.L.; Maxwell, J.T.; Letsinger, S.L.; Gholizadeh, H. A climatic deconstruction of recent drought trends in the United States. Environ. Res. Lett. 2015, 10, 044009. [CrossRef]

34. Sheffield, J.; Goteti, G.; Wood, E.F. Development of a 50-yr high-resolution global dataset of meteorological forcings for land surface modeling. J. Clim. 2006, 19, 3088-3111. [CrossRef]

35. Miralles, D.; Holmes, T.; De Jeu, R.; Gash, J.; Meesters, A.; Dolman, A. Global land-surface evaporation estimated from satellite-based observations. Hydrol. Earth. Syst. Sci. 2011, 15, 453-469. [CrossRef]

36. Nemani, R.R.; Keeling, C.D.; Hashimoto, H.; Jolly, W.M.; Piper, S.C.; Tucker, C.J.; Myneni, R.B.; Running, S.W. Climate-Driven Increases in Global Terrestrial Net Primary Production from 1982 to 1999. Science 2003, 300, 1560. [CrossRef]

37. Piao, S.; Wang, X.; Ciais, P.; Zhu, B.; Wang, T.A.O.; Liu, J.I.E. Changes in satellite-derived vegetation growth trend in temperate and boreal Eurasia from 1982 to 2006. Glob. Chang. Biol. 2011, 17, 3228-3239. [CrossRef]

38. Beck, H.E.; McVicar, T.R.; van Dijk, A.I.; Schellekens, J.; de Jeu, R.A.; Bruijnzeel, L.A. Global evaluation of four AVHRR-NDVI data sets: Intercomparison and assessment against Landsat imagery. Remote Sens. Environ. 2011, 115, 2547-2563. [CrossRef]

39. Tucker, C.J.; Pinzon, J.E.; Brown, M.E.; Slayback, D.A.; Pak, E.W.; Mahoney, R.; Vermote, E.F.; El Saleous, N.J. An extended AVHRR 8-km NDVI dataset compatible with MODIS and SPOT vegetation NDVI data. Int. J. Remote Sens. 2005, 26, 4485-4498. [CrossRef]

40. Mann, H.B. Nonparametric Tests against Trend. Econometrica 1945, 13, 245-259. [CrossRef]

41. Kendall, K. Thin-film peeling-the elastic term. J. Phys. D Appl. Phys. 1975, 8, 1449-1452. [CrossRef]

42. Ren, J.; Liu, H.; Yin, Y.; He, S. Drivers of greening trend across vertically distributed biomes in temperate arid Asia. Geophys. Res. Lett. 2007, 34. [CrossRef]

43. Zhao, X.; Tan, K.; Zhao, S.; Fang, J. Changing climate affects vegetation growth in the arid region of the northwestern China. J. Arid Environ. 2011, 75, 946-952. [CrossRef]

44. Kim, D.W.; Byun, H.R.; Choi, K.S. Evaluation, modification, and application of the Effective Drought Index to 200-Year drought climatology of Seoul, Korea. J. Hydrol. 2009, 378, 1-12. [CrossRef]

45. Zhang, X.; Li, M.; Ma, Z.; Yang, Q.; Lv, M.; Clark, R. Assessment of an evapotranspiration deficit drought index in relation to impacts on ecosystems. Adv. Atmos. Sci. 2019, 36, 1273-1287. [CrossRef] 